\title{
Selective Demethylation of 3-Phenoxyquinoxalin-2(1h)-one Acetate Derivatives
}

\author{
Yingang ZOU \& Bing MA \\ Beijing Institute of Technology, Beijing, China
}

\begin{abstract}
Using the previously reported novel quinoxaline scaffold, we synthesised the precursor compounds 1-12. According to the synthetic methodology, we described the discovery of a novel selective demethylation of quinoxaline derivatives with $\mathrm{AlCl}_{3}$ and $\mathrm{BBr}_{3}$, proposed a high selectivity demethylation approach. And this approach will provide a opportunity for developing new antioxidant base on phenolic hydroxyl.
\end{abstract}

KEYWORD: demethylation; diabetes; quinoxaline

\section{INTRODUCTION}

Diabetes mellitus is a metabolic disorder in which the body's ability to regulate blood glucose levels goes awry, either from defects in the secretion or in the activity of the hormone insulin.[1] Several hypotheses have been proposed to explain the pathogenic mechanism leading to diabetic complications and the prominent theory suggests that the activation of aldose reductase causes significant portion of the glucose enter into polyol pathway under hyperglycemia leading to the accumulation of sorbitol, which results in diabetic complications. High level in free radicals of reactive oxygen species (ROS) and in turn the oxidative stress under hyperglycemia is also ascribed to a major cause of the diabetic complications.

In order to develop new drugs for the therapy of the diabetic complications, we have designed and synthesized a series of quinoxaline derivatives as aldose reductase inhibitors (ARIs). ${ }^{[2]}$ Recently, we further designed a group of 3-phenoxyquinoxalin2(1h)-one acetate derivatives as ARI candidate which may have radical scavenging capability. ${ }^{[2]}$ During the synthesis of the compounds, phenolic methoxyl and methyl ester were present at the same time in the intermediate and therefore the selective demethylation of the phenolic methoxyl was a key step. Herein, we discuss about the demethylation method and its selectivity.
Table 1. Optimization of conditions for the demethylation of $\mathrm{AlCl}_{3}$ and $\mathrm{BBr}_{3}$

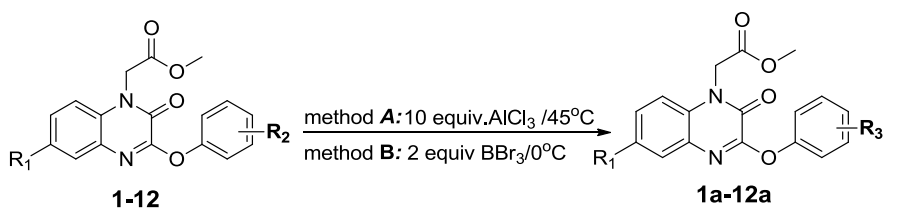

\begin{tabular}{|l|ll|l|l|l|}
\hline NO. & $\mathrm{R}$ & $\mathrm{R}_{2}$ & $\mathrm{R}_{3}$ & $\mathrm{Y} 1^{[\mathrm{a}]}$ & $\mathrm{Y}_{2}{ }^{[\mathrm{b}]}$ \\
\hline 1 & $\mathrm{~F}$ & $3,5-\left(\mathrm{CH}_{3} \mathrm{O}\right)_{2}$ & $3,5-(\mathrm{OH})_{2}$ & $82 \%$ & $30 \%$ \\
\hline 2 & $\mathrm{~F}$ & $3,4-\left(\mathrm{CH}_{3} \mathrm{O}\right)_{2}$ & $3,4-(\mathrm{OH})_{2}$ & no reaction & $25 \%$ \\
\hline 3 & $\mathrm{~F}$ & $4-\mathrm{CH}_{3} \mathrm{O}$ & $4-\mathrm{OH}$ & no reaction & $37 \%$ \\
\hline 4 & $\mathrm{C}$ & $3,5-\left(\mathrm{CH}_{3} \mathrm{O}\right)_{2}$ & $3,5-(\mathrm{OH})_{2}$ & $86 \%$ & $20 \%$ \\
\hline 5 & $\mathrm{C}$ & $3,4-\left(\mathrm{CH}_{3} \mathrm{O}\right)_{2}$ & $3,4-(\mathrm{OH})_{2}$ & no reaction & $38 \%$ \\
\hline 6 & $\mathrm{C}$ & $4-\mathrm{CH}_{3} \mathrm{O}$ & $4-\mathrm{OH}$ & no reaction & $27 \%$ \\
\hline 7 & $\mathrm{~B}$ & $3,5-\left(\mathrm{CH}_{3} \mathrm{O}\right)_{2}$ & $3,5-(\mathrm{OH})_{2}$ & $88 \%$ & $28 \%$ \\
\hline 8 & $\mathrm{~B}$ & $3,4-\left(\mathrm{CH}_{3} \mathrm{O}\right)_{2}$ & $3,4-(\mathrm{OH})_{2}$ & no reaction & $34 \%$ \\
\hline 9 & $\mathrm{~B}$ & $4-\mathrm{CH}_{3} \mathrm{O}$ & $4-\mathrm{OH}$ & no reaction & $19 \%$ \\
\hline 10 & $\mathrm{H}$ & $3,5-\left(\mathrm{CH}_{3} \mathrm{O}\right)_{2}$ & $3,5-(\mathrm{OH})_{2}$ & $85 \%$ & $31 \%$ \\
\hline 11 & $\mathrm{H}$ & $3,4-\left(\mathrm{CH}_{3} \mathrm{O}\right)_{2}$ & $3,4-(\mathrm{OH})_{2}$ & no reaction & $25 \%$ \\
\hline 12 & $\mathrm{H}$ & $4-\mathrm{CH}_{3} \mathrm{O}$ & $4-\mathrm{OH}$ & no reaction & $23 \%$ \\
\hline
\end{tabular}

[a] $\mathrm{Y}_{1}$ represent the isolated $\mathbf{1 a - 1 2 a}$ yield of method $A$ [b] $\mathrm{Y}_{2}$ represent the isolated 1a-12a yield of method B 
Table2. Optimization of conditions for the demethylation of $\mathbf{1 2}$ with $\mathrm{BBr}_{3}$

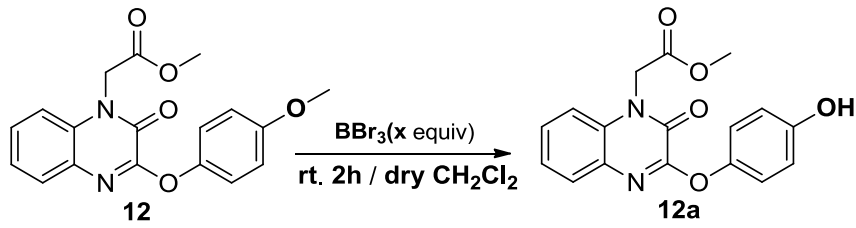

\begin{tabular}{|c|c|c|}
\hline entry & $\mathbf{B B r}_{\mathbf{3}}$ (x equiv) & Yield $^{[\mathbf{a}]}$ \\
\hline 1 & 0.5 & $40 \%$ \\
\hline 2 & 1 & $84 \%$ \\
\hline 3 & 1.5 & $53 \%$ \\
\hline 4 & 2 & $27 \%$ \\
\hline 5 & 2.5 & $13 \%$ \\
\hline 6 & 3 & trace \\
\hline 7 & 3.5 & trace \\
\hline
\end{tabular}

[a] Isolated yield based on $\mathbf{1 2}$

\section{RESULTS AND DISCUSSION}

The preparation of compounds 1-12 was based on the reported method.[2] An extensive literature research revealed that various lewis acids such as aluminum trihalides or boron trihalides have been used as mild demethylation agents, and in particular $\mathrm{AlCl}_{3}$ and $\mathrm{BBr}_{3}$ can be used to selectively remove the methyl of aromatic methoxy groups.[3] Thus, $\mathrm{AlCl}_{3}$ and $\mathrm{BBr}_{3}$ were used as demethylation reagents in the present study. Compounds 1-12 were treated with excess of $\mathrm{AlCl}_{3}$ (method $\left.\mathrm{A}\right)$ at $45^{\circ} \mathrm{C}$ or $\mathrm{BBr}_{3}$ (method B) at room temperature as shown in Table1. [4,5]

By the method $\mathrm{A}$, the reaction of compounds $\mathbf{1}, \mathbf{4}$, 7, and $\mathbf{1 0}$ were observed with $\mathrm{AlCl}_{3}$ in high yields of $82 \%, 86 \%, 88 \%$, and $85 \%$, respectively, while no reaction was found for the remained compounds. However, by method $\mathrm{B}$ the reaction with $\mathrm{BBr}_{3}$ was observed for all substrates $\mathbf{1 - 1 2}$, but it only gave low yield of $19 \%$ to $38 \%$. Therefore, the reaction condition was further optimized for the method B with 12 as a sample of the substrates, and the product 12a was obtained in good yield of $84 \%$ using one equivalent of $\mathrm{BBr}_{3}$ (Table 2). Less or more equiv $\mathrm{BBr}_{3}$ all resulted in trace product or in low yield of $13 \%$. These results suggest that the mount of $\mathrm{BBr}_{3}$ could greatly affect the yield.

\section{CONCLUSION}

The present study found that the lewis acid $\mathrm{AlCl}_{3}$ as demethylation agent was specific for the demethylation of meta-methoxyl of aromatic ring of quinoxaline derivatives in high yield. However, $\mathrm{BBr}_{3}$ could be used for the demethylations of all substrates and lead to good yields using a suitable mount of the demethylation agent.

\section{REFERENCES}

[1] W. H. Tang, et al. 2012. Aldose reductase, oxidative stress, and diabetic mellitus, J. Front. Pharmacol., 3: 87.

[2] Y. C. Yang, et al. 2012. An Efficient Synthesis of Quinoxalinone Derivatives as Potent Inhibitors of Aldose Reductase Chemmedchem. 7: 823-835; b) B. B. Wu, et al. 2013. Synthesis and Structure-Activity Relationship Studies of Quinoxaline Derivatives as Aldose Reductase Inhibitors. ChemMedChem 12: 1913-1917.

[3] Enoch A. et al. 2012. Selective methoxy ether cleavage of 2,6-dimethoxyphenol followed by a selective acylation. Tetrahedron Lett 53: 11-14.

[4] Max v. et al. 2012. Rhodium-Phosphoramidite Catalyzed Alkene Hydroacylation: Mechanism and Octaketide Natural Product Synthesis. J. Am. Chem. Soc. 134:15022-15032.

[5] Y. Liu. et al. 2003. Thyroid Receptor Ligands.1. Agonist Ligands Selective for the Thyroid Receptor. J.Med. Chem 46:1580-1588. 